\title{
A new basal osmylid neuropteran insect from the Middle Jurassic of China linking Osmylidae to the Permian-Triassic Archeosmylidae
}

Vladimir V. Makarkin, Qiang Yang, and Dong Ren

Acta Palaeontologica Polonica 59 (1), 2014: 209-214 doi: http://dx.doi.org/10.4202/app.2011.0018

Anew osmylid neuropteran insect Archaeosmylidia fusca gen. et sp. nov. is described from the Middle Jurassic locality of Daohugou (Inner Mongolia, China). Its forewing venation differs from that of other hitherto known osmylids by a set of plesiomorphic features. This genus is considered here as representing a basal group of Osmylidae. The PermianTriassic family Archeosmylidae comprises the genera Archeosmylus, Babykamenia, and Lithosmylidia . Archaeosmylidia and Archeosmylidae share the few-branched CuP, the absence of zigzag vein pattern, and the scarcity of the crossveins in the radial space. We estimate that Osmylidae might have originated in the Triassic from some "archeosmylid-like" ancestor.

Key words: Neuroptera, Osmylidae, Archeosmylidae, Jurassic, Daohugou, China.

Vladimir V. Makarkin [vnmakarkin@mail.ru], College of Life Sciences, Capital Normal University, Beijing, 100048, China and Institute of Biology and Soil Sciences, Far Eastern Branch of the Russian Academy of Sciences, Vladivostok, 690022, Russia; Qiang Yang [yq11 1984@ 126.com] and Dong Ren [rendong@ mail.cnu.edu.cn] (corresponding author), College of Life Sciences, Capital Normal University, Beijing, 100048, China.

This is an open-access article distributed under the terms of the Creative Commons Attribution License (for details please see creativecommons.org), which permits unrestricted use, distribution, and reproduction in any medium, provided the original author and source are credited. 
